Estudios sobre armas antiguas, arte militar $\mathrm{y}$ vida cultural en oriente y occidente

XXXIX (2019), pp. 93-108

ISSN: 0436-029X

https://doi.org/10.3989/gladius.2019.05

\title{
NUEVAS E IGNORADAS NOTICIAS SOBRE LA KÂHINA Y LA CONQUISTA ÁRABE DEL ÁFRICA BIZANTINA: DE REINA DE LOS BEREBERES A REINA DE LOS ROMANOS
}

\author{
NEW AND IGNORED NEWS ABOUT KAHINA AND THE ARAB CONQUEST \\ OF BYZANTINE AFRICA: FROM QUEEN OF THE BERBEERS \\ TO QUEEN OF THE ROMANS
}

\author{
POR \\ José Soto Chica* y Maila García Amorós**
}

\section{RESUMEN - ABstract}

El sometimiento del África bizantina por los ejércitos omeyas tiene su eje central en los relatos, cargados de leyenda y a menudo contradictorios, de la llamada «Guerra de la Kâhina». Esta misteriosa mujer, supuesta reina de una tribu bereber del monte Aurés, ha condicionado los intentos de la historiografía contemporánea por establecer un relato coherente desde el punto de vista cronológico, militar y cultural, de la definitiva conquista árabe del África bizantina. El objetivo de este trabajo es poner en valor el texto más antiguo sobre la Kâhina, la Crónica de los árabes, recogido en la obra de Elías de Nísibe. Esto nos permitirá contextualizar adecuadamente a la mítica Kâhina y enmarcar su resistencia a la expansión islámica en un plano plenamente histórico, determinado por la resistencia bizantina ante la expansión árabe por el control del norte de África.

The stories, full of legend and often contradictory, of the so-called «Kâhina's War» have as a central focus the subjugation of Byzantine Africa by the Umayyad armies. This mysterious Kâhina, supposed queen of a Berber tribe of Mount Aurés, has conditioned the attempts of contemporary historiography to establish a coherent chronological, military and cultural account of the definitive Arab conquest of Byzantine Africa. The objective of this work is to assess the oldest text about Kâhina, the Chronicle of the Arabs, collected in the work of Elías Bar Shinaya. This will allow us to adequately contextualize the mythical Kâhina and frame their resistance to Islamic expansion in a complete historical context, determined by the Byzantine resistance to the Arab expansion for the control of North Africa.

\section{Palabras Clave - Keywords}

Kâhina; Crónica de los árabes; Elías Bar Shinaya; conquista árabe; África bizantina.

Kâhina; Chronicle of the Arabs; Elijah Bar Shinaya; Arab conquest; Byzantine Africa.

\section{CÓMO CITAR ESTE ARTículo / Citation}

Soto Chica, J. y García Amorós, M. (2019): «Nuevas e ignoradas noticias sobre la Kâhina y la conquista árabe del África bizantina: de reina de los bereberes a reina de los romanos». Gladius, XXXIX: 93-108. https://doi. org/10.3989/gladius.2019.05

* Departamento de Historia Medieval y Técnicas y Ciencias Historiográficas, Universidad de Granada, josesotochica @ugr.es / ORCID iD: https://orcid.org/0000-0003-3460-1843

** Departamento de Filología Griega y Filología Eslava, Universidad de Granada, maila@ugr.es / ORCID iD: https:// orcid.org/0000-0003-0287-3641 


\section{A. LA KÂHINA Y LA CONQUISTA ÁRABE DE CARTAGO: PARADIGMA HISTORIO- GRÁFICO Y REALIDAD HISTÓRICA}

La pugna sostenida por árabes y bizantinos por el dominio de los extensos y ricos territorios que constituían el África bizantina fue sin duda la más dura y larga de cuantas entablaron en el siglo VII. A lo largo de más de 50 años, los ejércitos árabes avanzaron y retrocedieron en varias ocasiones, mientras que las unidades bizantinas no sólo disputaron el territorio a los invasores, sino que, en no pocas ocasiones, pasaron a la ofensiva, desembarcando tropas en Tripolitania y Pentápolis e incluso recuperando brevemente el control sobre estos territorios (Soto Chica, 2015b: 541-606).

Esta larga y dura guerra ha sido tradicionalmente tergiversada con el recurso de centrar la atención en la resistencia bereber que, en buena medida, se desliga de la bizantina y a la que ésta última sirve de comparsa. El punto de partida para esta reinterpretación de los hechos lo constituye la gran expedición de 647-648, que supuestamente desarboló la estructura de poder y dominio bizantino en África, hasta el punto de que ésta no pudo ser restablecida durante años. Además, cuando el poder imperial volvió a controlar Cartago, su autoridad no fue ya mucho más allá de los alrededores inmediatos de la antigua capital africana. Se iniciaba así una fase nueva en la que las tribus bereberes, cada vez más desligadas de la autoridad e influencia bizantinas, se transformaban en el eje en torno al cual giraba la resistencia frente al invasor árabe.

La vigencia de este esquema sigue siendo hegemónica, más por la falta de interés en examinarlo que por su solidez. Así por ejemplo, María Elvira Gil Egea afirma: «Los responsables de la defensa de África no fueron las fuerzas bizantinas que, tras haber sido derrotadas en un primer encuentro junto a Sufetula, se replegaron sobre la capital, sino los líderes moros, en particular Kusayla/Kasila y a su muerte, la Kâhina, reina de los bereberes del Aurés» (Gil Egea, 2015: 517-541). La tesis es tan vieja como la Historiografía contemporánea sobre la conquista islámica del Magreb, cuyo paradigma historiográfico fue ya perfilado por Fournel y Diehl en el siglo XIX (Fournel, 1875: vol. 1, 144-145; Diehl, 1896: 568).

Las ideas de Fournel y más aún las de Diehl pronto se transformaron en «lugares comunes» y, para la inmensa mayoría de los estudiosos, persisten hasta hoy con muy escasas variaciones de matiz. Se trata de un esquema historiográfico aceptado e indiscutido que, al abordar los últimos cincuenta años del África bizantina, 648-698, centra casi por completo su atención en dos figuras semilegendarias: Kusayla y la Kâhina, a las que se ha querido convertir a toda costa en símbolos de la resistencia bereber, con sus arquetípicas, coloniales y cambiantes facetas de barbarismo y heroísmo.

Sin embargo, desde comienzos del presente siglo y gracias a testimonios de fuentes contemporáneas a los hechos, sabemos que la autoridad imperial se restableció de inmediato tras la gran expedición de 647-648 y que esa restauración del poder bizantino se extendió no sólo sobre Cartago, sino también sobre la totalidad de Bizakia ${ }^{1}$ y de Numidia, así como sobre las Mauritanias, Tripolitania e incluso a puntos de la debelada Pentápolis. Estas fuentes contemporáneas son la llamada Geografía de Ananias de Shirak (Ananías de Shirak, 1992) escrita hacia 679, y las Notitiae Graecorum Episcopatuum (Migne, 1863, CVII, col. 329), que para su parte occidental, África, Italia e Hispania, fueron terminadas después de 656 pero antes de 665

\footnotetext{
1 Preferimos usar el término de Bizakia, que en el siglo VII englobaba a las antiguas Bizacene y Proconsular, como atestiguan diversas fuentes (Maldonado Villena y Soto Chica, 2016; Ananías de Shirak, 1992, 50 A y 50 B; Al-Bekri, 1913: 4).
} 
(Zuckerman, 2002: 170-175; Modéran, 2003: 786; Benabbès, 2004: 64-65 y 232-234; Kaegi, 2010: 147-148).

No hubo vacío de poder, tampoco existe ningún testimonio contemporáneo que acredite la existencia, en el siglo VII, de principados bereberes independientes del poder bizantino dentro de los límites del exarcado africano. De hecho, el análisis exhaustivo de las fuentes islámicas primarias refleja con claridad la realidad de la conquista árabe del África bizantina: que fue contra las fuerzas romanas y no contra supuestos principados bereberes contra quienes los ejércitos islámicos tuvieron que entablar los más duros combates.

¿Pero no están centrados los testimonios de las fuentes islámicas en la pugna de los ejércitos califales contra dos príncipes bereberes? Pues bien, Kusayla aparece en las fuentes más seguras y antiguas como un comandante de tropas romanas. De hecho, todo apunta a que Kusayla era el Duque o Turmarca de Numidia en 683 y que en 688, o bien era una suerte de comandante supremo al mando de los ejércitos africanos, o bien el Exarca de Cartago (Soto Chica, 2015a: 493-501). En cuanto a la mitificada Kâhina, contaba con una genealogía romana, recogida por Ibn Jaldûn (Ibn Jaldûn, 1925: 218) y con un esposo y un hijo romano, lo que nos ha llegado a través de Ibn 'Idhari (1901-1904: 27). Además, no sólo comandaba tropas romanas y bereberes y tuvo sus mayores centros de lucha y resistencia en ciudades romanas y en zonas fuertemente romanizadas ${ }^{2}$, sino que además, el testimonio más antiguo y seguro que poseemos sobre ella, la designa no como «reina de los bereberes», sino como «reina de los romanos». Pero además, no es a ella, sino a unos «reyes de los romanos» a quienes la fuente en cuestión atribuye la pavorosa derrota sufrida por Hassân ibn al-Nu'man al-Ghassâní a fines del verano de 697 y que le obligó a retirarse a Kusur Hassan, fortaleza situada en los límites entre Tripolitania y Pentápolis y quedarse allí en espera de refuerzos.

\section{B. LA CRONOGRAFÍA DE ELÍAS BAR SHINAYA, LA CRÓNICA DE LOS ÁRABES Y LA KÂHINA}

Habitualmente se considera que el testimonio más antiguo de cuantos conservamos que menciona a la Kâhina se encontraba en la obra de Al-Wākịīi. Este historiador, nacido en 749 y muerto en 823 , escribió hacia 815 una obra sobre las conquistas árabes que fue ampliamente usada por historiadores islámicos posteriores como Ibn Al-Athir en el siglo XIII, y gracias a ello hemos podido salvar parte de sus noticias y entre ellas, la referente a la Kâhina. Al-Wākịīī fue un historiador muy criticado por los eruditos islámicos medievales, pero, como destacó Yves Modéran, su testimonio sobre la Kâhina es muy sobrio y está muy alejado de las posteriores construcciones legendarias de la historiografía musulmana (Modéran, 2006: 162-163).

A continuación, contamos con el testimonio de Ibn 'Abd al-Hakam ('Abd al-Hakam, 1964), quien escribió su obra sobre la conquista del norte de África y España hacia 860. De modo que esos dos testimonios del siglo IX eran la base a partir de la cual se podía intentar rescatar a la Kâhina del pesado manto de pintorescas anécdotas y leyendas con el que los posteriores genealogistas, historiadores y geógrafos musulmanes cubrieron su figura y por mor del cual a menudo se ha dudado de su existencia real.

Ahora bien, gracias a la mediación de Elías Bar Shinaya, obispo de la ciudad de Nísibe a comienzos del siglo XI, se nos han salvado las que son, sin duda, las noticias más antiguas sobre la Kâhina. Elías de Nísibe nos indica que tomó dichas noticias de una obra árabe hoy

2 Los principales centros de resistencia y lucha vinculados a la Kàhina fueron las ciudades romanas de Tacapes, Gabes, Tisrus, El-Djem, Mascula, Bichr, Tabraca, Tabarca, Bagai, Bagralla y Iustiniana Capsa, Gapsa. 
perdida, escrita en torno a mediados o finales del siglo $\mathrm{VIII}^{3}$, esto es, alrededor de un siglo antes de que Ibn 'Abd al-Hakam escribiera su obra y entre treinta y sesenta años antes de que AlWāḳidī hiciera lo propio con su hoy perdida obra. Se trata de la obra anónima conocida como Series Temporum Saracenorum es decir, Crónica de los árabes, que fue la fuente principal de Elías de Nísibe para los primeros 90 años de la hégira junto con la perdida obra histórica del sabio persa de finales del siglo VIII e inicios del IX, Müsä Kwarizmi. En concreto, Elías cita la Crónica de los árabes treinta y dos veces para los años 10 a 90 de la hégira, 942-1020 de la era seleúcida, es decir, para los años 632 a 709 de nuestra era, y 46 veces la de Kwarizmi para los años 11 a 91 . El resto de fuentes que Elías cita para esos primeros años de la hégira junto con La Crónica de los árabes y con la perdida obra de Kwarizmi, son obras siriacas o anónimas árabes, de gran antigüedad. Tal es el caso de la obra de Jacobo de Edesa, historiador siriaco que terminó su obra en 692, o de la Crónica de los reyes árabes, obra anónima escrita en árabe, que Elías usa para los años 1 a 9 de la hégira y para el año 46, y que parece haber sido redactada en el primer tercio del siglo VIII. De hecho, Elías de Nísibe usa y reproduce el texto árabe de la Crónica de los árabes en los años 10, 24, 25, 26, 27, 28, 29, 31, 38, 42, 43, 44, 45, 47, 52, $62,63,66,68,69,70,71,72,77,78,79,81,82,83,84,85$ y 90.

Es muy significativo que en las doce entradas de su Cronografía en las que Elías Bar Shinaya usa la anónima Crónica de los árabes junto con dos obras siriacas y dos árabes, sean de gran antigüedad y se remonten a fines del siglo VII, al VIII o a inicios del IX. Así Elías Bar Shinaya usa la Crónica de los árabes en los años 10 y 66 de la hégira junto con Jacobo de Edesa. En el año 82 de la hégira usa la Crónica de los árabes junto con la obra de Isodenah metropolitano de Basra, quien escribía en la primera mitad del siglo VIII. Por último, usa y reproduce 9 veces la Crónica de los árabes junto con fragmentos de la obra de Müsä Kwarizmi, quien escribía en torno a 810. En concreto, lo hace en los años 25, 42, 43, 44, 45, 47, 52, 83 y 84 de la hégira. De todo ello es fácil deducir la importancia y antigüedad de esta fuente anónima escrita en árabe y cuya parquedad, sobriedad y fiabilidad son notables.

Ahora bien, se podría argumentar que el testimonio de la Crónica de los árabes recogido en la Cronografia de Elías Bar Shinaya es bien conocido y no contradice al resto de los testimonios islámicos que conocemos sobre la Kâhina. De hecho, es conocido en Occidente desde 1820, cuando el orientalista inglés Claudius James Rich se hizo en Mosul con el único manuscrito de la Cronografía de Elías de Nísibe. Este manuscrito, sin embargo, tardó casi un siglo en ser accesible a los historiadores pues, aunque en 1884 Friedrich Baethgen ya ofreció una edición y una traducción al alemán de parte de la Cronografía (Elías de Nísibe, 1884 [2006²]), no fue hasta 1909-1910, cuando se procedió a la completa y cuidada edición del texto siriaco y árabe, esta vez acompañado por una traducción latina, a cargo de Brooks y Chabot (Elías de Nísibe, 1909-1910). Fournel, Dihel y los demás eruditos franceses del XIX no usaron la edición de Baethgen, pues ninguno de ellos la cita. Además, la casi simultánea aparición de la traducción al francés de Delaporte del Opus Chronologicum de Elías de Nísibe en 1910 lo convirtió en el texto de referencia. La facilidad de contar con una traducción francesa motivó que la obra de Delaporte haya sido la obra de consulta general de la mayoría de los historiadores hasta hoy. En dicha traducción, la Kâhina aparece dos veces, en el año 78 de la hégira, año 1008 de la era seleúcida, 30 marzo de 697 a 29 de marzo de 698 (Elías de Nísibe, 1910: 95),

3 La antigüedad y sobriedad de las noticias de Elías de Nísibe en relación a la historia de la Kâhina fue ya resaltada por Modéran. Si bien el sabio francés no se detuvo a dilucidar si tales noticias procedían de la Crónica de los árabes que fecha en el siglo VIII, o del sabio persa de fines del VIII e inicios del IX Al- Khwarizmi. Tampoco se percató de la notable diferencia entre el texto árabe y el siriaco, sino que se limitó a leer la traducción latina que cita en su artículo (Modéran, 2006: 161-162). 
y en el año 84 de la hégira, 1014 de la era seleúcida, 24 de enero de 703 a 23 de enero de 704 (Elías de Nísibe, 1910: 97).

En esas dos entradas supuestamente centradas en la Kâhina Delaporte traduce:

An 78. - A comencé le vendredi 30 Adar de l'an 1008 des Grecs [30 mars 697 de J.-C.].

En lequel le Gassanide Hasān, fils de Nū‘man, s'avança sur l' ordre de ‘Abd el Melik, fils de Nerwan, dans le pays des Romains, et revint victoriex. La reine des Berbères le recontra, le vainquit ainsi que touts ceux qui étaient avec lui. Hasān lui échappa; tous ceux qui étaient avec lui périrent et furent tués (Chonique des Arabes) (Elías de Nísibe, 1910: 95).

An 84. - A comencé le mercredi 24 Kanun II de l'an 1014 des Grecs [24 janvier 703 de J.-C.]. En lequel ،Abd Allah, fils de ،Abd el melik, fils de Merwan, rébatit la ville de Mopsueste. - En lequel Hasān, fils de Nu‘man, entra en Afrique. La reine des Berbères partit pour le combattre. Elle fut tuée ainsi qu' une grande partie de l' armée qui était avec elle (Chonique des Arabes) (Elías de Nísibe, 1910: 97).

Hasta aquí todo bien. Se puede incluso contrastar la traducción francesa de Delaporte con la alemana de Baegen y constatar una completa similitud:

Jahr 78; begann am Freitag den 30. Âdar, 1008 gr. Z.

In Ihm zog der Ġassanide Hassân ibn en- Nu'mân auf Befehl 'Abd el Melik ibn Merân's nach dem Gebiet der Grieschen und kehrte siegreich zurück. Dann stiess auf ihn die Königin der Berber und besiegte ihn ind Alle, die bei ihn waren. Da floh Hassân vor ihr, und Alle, welche bei ihm waren kamen um und wurden getödtet.

Chronik der Araber (Elías de Nísibe, 1884: 119).

Jahr 84; begann am Donnerstag den 4. KânûnII, 1014 gr. Z.

In ihm erneuerte 'Abd Allah ibn «Abd el melik ibn Nerwân die Stadt Mopsueste. In ihm zog Hassân ibn en Nu'mân nach Afrika. Da zog die Königin der Berber aus, um mit ihm zu kämpfen: sie wurde aber getödtet nebst Vielen aus ihrem Hee.

Chronik der Araber (Elías de Nísibe, 1884: 120).

Se puede constatar también la casi perfecta concordancia de las traducciones alemana y francesa con la latina llevada a cabo por Brooks y Chabot:

Annus 78 iniit praeparatione die $30^{\circ}$ adar anni 1008 Graecorum- -Series temporum Saracenorum.

Eo Hassan filius Nu'manis Ghasanita mandato Abd al Malik filii Marwan dicionem Romanorum invasit, et cum victoria exiit. Et regina barbarorum ei obviam venit eumque superávit et omnes qui cum eo erant perierunt et occisi sunt (Elías de Nísibe, 1909-1910: 154).

Annus 84 iniit feria $4^{\mathrm{a}}$ die $24^{\circ}$ kanun II annii 1014 Graecorum. -Khuwarizmensis. Series temporum Saracenorum.

Eo Abdallah filius Abd al malik filli Marwan Mepsostiam (i. e. Mopsuestiam) urbem renovavit. Et eo Hassan filius Nu'manis regionem Africae invasit et exit regina barbarorum cum eo pugnatura, et ipsa occisa est et multi ex exercitu qui cum ea erat (Elías de Nísibe, 1909-1910: 156).

Lo mismo ocurre al acudir al texto siriaco escrito en 1018, probablemente por el propio Elías de Nísibe. La correspondencia con sus traductores al latín, al francés y al alemán, es casi perfecta. Sin embargo, si se acude al texto árabe original copiado en 1018 por Elías de Nísibe de la obra original árabe anónima, que cita como Crónica de los árabes, la sorpresa es mayúscula. En primer lugar, porque en el texto árabe correspondiente al primero de los pasajes arriba 
reproducidos en sus traducciones alemana, francesa y latina, no aparece la Kâhina, ni ninguna otra «Reina de los bereberes». La derrota sufrida por Hassân ibn al-Nu'man al-Ghassâní le es infligida por unos «reyes» y no por una reina. Por otra parte, aunque las dos ediciones existentes del texto árabe, la de Baethgen y la de Brooks y Chabot, señalan a continuación de la palabra «reyes» una palabra poco clara por mor de una mancha de humedad en el manuscrito, todo apunta a que, teniendo en cuenta el contexto, esa palabra sólo puede ser «romanos». Así pues, en la noticia más antigua y segura sobre la derrota de Hassân ibn al-Nu'man al-Ghassâní, no aparece la Kâhina, sino unos «reyes de los romanos», un término que en la historiografía islámica temprana a menudo apunta simplemente a gobernadores, generales y funcionarios de alto rango ${ }^{4}$.

Por ello, en el caso que nos ocupa hay poca duda sobre que bajo ese nombre de «reyes»

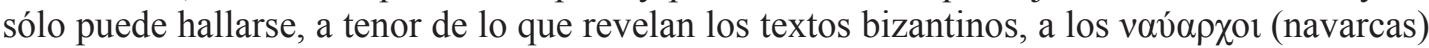

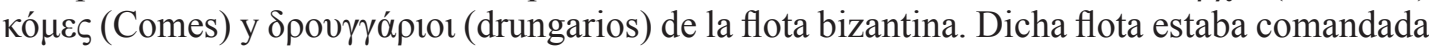
por el $\sigma \tau \rho \alpha \tau \eta \gamma o ́ \varsigma$ (comandante supremo) Juan el patricio, así como los mandos del ejército africano que, en 686, era todavía uno de los nueve grandes ejércitos del imperio, como indica una carta del emperador Justiniano II al papa Juan V (Migne, 1862: MPL096, 0427-0444B, 0680-0690) y probablemente al general que, según Al-Bekri (1913: 23), comandaba el ejército de la Kàhina cuando ésta derrotó a los árabes en Tacape, Gabes y que, según nos aclara el geógrafo del siglo XI, había sido el lugarteniente de Kusayla.

En el segundo texto de la Crónica de los árabes que sirvió de base a la entrada siriaca de la Cronografia también aparece la Kâhina, aunque no con su nombre propio. Sin embargo, sorprendentemente la mención a una «reina de los bereberes» no aparece por ningún lado, sino que lo que dice el texto árabe original de la Crónica de los árabes es: «Malkatal-rum» literalmente «reina de los romanos». Ofrecemos a continuación el texto árabe original acompañado de la traducción al español de los dos fragmentos del texto árabe de Elías de Nísibe que nos ocupan

$1^{\mathrm{o}}$

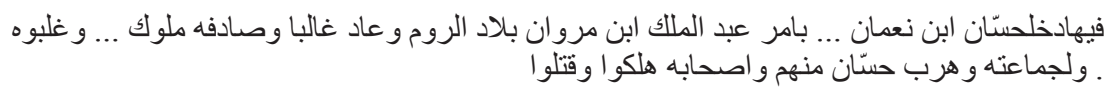

(Elías de Nísibe, 1909-1910: 74-75)

En el que Ḥassān ibn Nu'mān entró [...] por orden de 'Abd al-Malik ibn Marwān en la tierra de los rūm y volvió victorioso; se topó con reyes [...] que le vencieron junto a sus tropas. Hassān huyó de ellos y sus acompañantes perecieron y fueron asesinados.

4 Tal es el conocido caso del patricio Gregorio, exarca de Cartago, al que las fuentes islámicas otorgan el título de "rey" con suma frecuencia, al igual que se lo otorgan al anónimo Exarca de Cartago y a otros jefes y mandos bizantinos africanos, así como al papa de Roma que también recibe de los autores árabes el título de rey. Los ejemplos son abundantísimos y por eso señalaremos sólo algunos de ellos, en relación a Ifriqiya. Ibn 'Abd al-Hakam llama rey al patricio Gregorio, exarca de Cartago (Ibn 'Abd al-Hakam, 1966: 21). El geógrafo persa del siglo IX Ibn Khurradâdhbih, al hablar de Sufetula, llama "Rey Jurjîr” al Exarca de Cartago, el patricio Gregorio y el mismo título le otorga al rey visigodo Rodrigo y al bíblico Goliat (Ibn Khurradâdhbih, 1949: 7-8).El geógrafo del siglo XII Idrisi otorga el título "Rey de los romanos de Ifriqiya" al exarca Gregorio, al que poco más tarde, llama "Gran rey" (Idrisi, 2016).Al-Maliki, por su parte, otorga el título de "Rey" al anónimo exarca derrotado por Hassân ibn al-Nu'man al-Ghassâní en 697 y el de "Reyes", al referirse en conjunto a la Kâhina y a los demás jefes romanos y bereberes, que seguían oponiéndose al dominio islámico de Ifriqiya tras la primera toma de Cartago (Al-Maliki, 1969: 143), y lo mismo hace Ibn Al-Athir (1898: 29). El geógrafo del siglo IX Ibn Rustih otorga el título de "Rey" tanto al papa de Roma, como a los reyes anglosajones de la heptarquía inglesa del momento: «Los siete reyes de la isla de Bart'iniya» (Ibn Rustih, 1949: 69-70 y 73-74). Queda claro pues que el título de "reyes" era otorgado a cualquier extranjero que ostentara un poder significativo, ya fuera éste un rey en el pleno sentido del término para un occidental, ya un papa de Roma, ya un exarca.

5 La traducción del texto árabe al español ha corrido a cargo del profesor titular del Departamento de Estudios Semíticos de la Universidad de Granada José Martínez Delgado. 
$2^{\circ}$

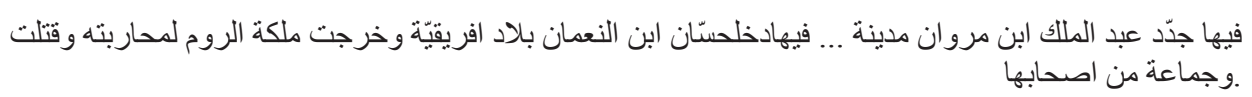

(Elías de Nísibe, 1909-1910: 154-156)

En el que 'Abd al-Malik ibn Marwān restauró la ciudad de [...] (Mopsuetsia) En el que Hassān ibn al-Nu'mān entró en la tierra de Ifriqiyya. La reina de los rūm salió a presentarle batalla y fue muerta junto con sus acompañantes.

La errónea traducción como «reina de los bereberes» se debe a dos motivos. El primero es que los traductores se desentendieron del texto árabe original y se centraron en el siriaco, que no era sino una composición realizada a partir de una traducción, no del todo fiel, como hemos visto, del original árabe. Recordemos que Elías de Nísibe tenía ante sí el texto árabe original de la anónima Crónica de los árabes, sin embargo, no se limitó a traducir del árabe al siriaco, sino que, probablemente influido por el ambiente historiográfico de su época, decidió congraciar el texto original de la Crónica de los árabes con el resto de las obras islámicas que consultó ${ }^{6}$ y que desde la segunda mitad del siglo IX, afirmaban una y otra vez que la resistencia ante el avance árabe la encabezó una reina bereber: la Kâhina. Así pues, Elías transmutó «reyes de los romanos» por «reina de los bereberes» y «reina de los romanos» por «reina de los bereberes».

La obra de Elías de Nísibe es la obra de un gran erudito muy interesado por la cronología y por ende, por la astronomía y las matemáticas. Se interesó también por verter al siriaco y al árabe la información ofrecida por autores griegos y romanos como Ptolomeo, Eusebio de Cesarea o Sócrates Escolástico, por traducir al árabe las noticias de autores siriacos como Jacobo de Edesa o Juan el Jacobita y por trasladar al siriaco las noticias de autores árabes como Al-Tabari o Abu Bekrj Mohammed. Cuando Elías afirma expresamente que su fuente para una noticia es la Crónica de los árabes, escrita en árabe, hay que entender que no traducía dicha obra del árabe al siriaco y viceversa, lo que sería absurdo, sino que copiaba el texto árabe original que estaba consultando y hacía su traducción al siriaco.

Casi novecientos años más tarde, al editar y traducir a Elías de Nísibe, Baethgen, Brooks y Chabot y Delaporte se limitaron a leer y traducir el texto siriaco y no advirtieron sus significativas diferencias con el original árabe $\mathrm{o}$, al menos, no lo señalaron en ninguna nota a pie de página o comentario. En este sentido, tanto Baegen como Delaporte concluyeron que el propio Elías de Nísibe era el responsable de la copia de los dos textos de la Crónica de los árabes que aquí nos ocupan. En el caso de Baegen, son identificados con la letra E en la edición del texto árabe (Elías de Nísibe, 1884: 6 y ss., 1910: XIII). Con el paso del tiempo cayó en el olvido que la Crónica de los árabes, no señalaba a una «reina de los bereberes» como causante de su pavorosa derrota, sino a unos «reyes de los romanos».

Esto último es muy relevante, pues pone de acuerdo a la fuente árabe más antigua, la Crónica de los árabes, con lo que afirmaban las siete fuentes bizantinas que narraban la pérdida, reconquista y definitiva caída de la Cartago bizantina: Hassân ibn al-Nu'man al-Ghassâní fue derrotado por Juan el patricio y sus generales y no por ninguna reina guerrera venida desde las montañas del Aurés. Más aún, la traducción del texto árabe de la Crónica de los árabes conservado en la entrada del año 84 de la hégira, rescata el verdadero contexto cultural y político de la auténtica Kâhina: que era una «reina de los romanos» y no una «reina de los bereberes». En

6 Elías de Nísibe cita expresamente las obras escritas en árabe de los siguientes autores: Al-kwarizmi, 'Obeïd Allah Ibn Ahmed, Al-Tabari, Tâbit Ibn Sinân Ibn tâbit, y Abu Bekrj Mohammed. Junto con estos autores árabes, Elías cita tres obras anónimas árabes: la Crónica de los reyes árabes, obra antiquísima que sólo usa para los años 1 a 9 de la hégira y para el año 46, la Crónica de los árabes y el Libro de la crónica. (Elías de Nísibe, 1884: 4-6, 1910: XIII). 
otras palabras, se trataba de una líder carismática de los romano-africanos del exarcado bizantino y no de una reina independiente de una tribu bereber, como ya señalaban muchas noticias conservadas por los historiadores y geógrafos musulmanes más antiguos y fiables.

Con casi toda probabilidad y, aunque los traductores modernos se hubiesen percatado de la notable diferencia entre el texto árabe y el siriaco, una vez más, la reconstrucción historiográfica se impuso a la realidad histórica. Dicho de otro modo, cuando en 1885 y 1910, Baethgen, Brooks y Chabot y Delaporte, tradujeron la obra de Elías de Nísibe, el esquema historiográfico perfilado por Fournel, Diehl y otros historiadores franceses, basado en la suma de los intereses y experiencias coloniales y en las tardías fuentes árabes que se habían conservado directamente, estaba tan asentado que todos ellos tradujeron el texto siriaco y se olvidaron del original en árabe a fin de no perturbar lo que estaba generalmente aceptado y de que no hubiese desacuerdo entre la Cronografía de Elías de Nísibe y las fuentes árabes escritas entre 860 y 1325. Téngase en cuenta, no obstante, que estas fuentes eran más tardías y menos fiables que la que salvó Elías de Nísibe en su Cronografía.

Ahora bien, hemos visto que la Crónica de los árabes es la única fuente de Elías para el año 78 de la hégira, sin embargo, para el año 84 el autor cita, no sólo la Crónica de los árabes sino también al persa Al-Khwarizmi como fuente de sus noticias. ¿No procederá entonces la noticia sobre la «reina de los romanos» del persa Al-Khwarizmi y no del autor de la Crónica de los árabes? La respuesta es no, porque la Cronografía sigue siempre el mismo procedimiento de cita y uso de fuentes, en el que la primera noticia del año que se está narrando corresponde a la primera fuente citada, hecho que fue advertido por Baegen (Elías de Nísibe, 1884: 6). En este caso, el año 84, la primera noticia corresponde al escenario bélico de Asia Menor y en concreto a la ciudad de Mopsuetsia y por eso aparece como primera fuente citada la obra del persa Al-Khwarizmi ${ }^{7}$, que en la Cronografía es la fuente principal para las campañas árabes en Asia Menor, mientras que la segunda noticia es la de la derrota y muerte de la «reina de los romanos». En correspondencia, Elías cita la Crónica de los árabes, que es la fuente que le proporcionó las otras dos noticias sobre la conquista musulmana de África y que recoge previamente en su obra: la del año 27 de la hégira en la que narra la primera y exitosa campaña árabe en el exarcado cartaginés, la del año 647-648, y la del año 78, que narra el ataque árabe contra Cartago en 697, afortunado en un principio, pero que acabó con una terrible derrota árabe infringida por los «reyes de los romanos». Está claro pues que es a la Crónica de los árabes a donde hay que mirar para reconocer la fuente de las noticias africanas del año 84 de la hégira de la Cronografía de Elías de Nísibe. Puesto que la Crónica de los árabes es una fuente centrada en las campañas árabes de los primeros califas y puesto que la información es siempre precisa y sobria, parece que sus noticias sobre la Kâhina son muy fiables y constituyen un sólido argumento. Este argumento se suma a otros muchos, a favor de que fueron los rum, los romanos, los bizantinos, y no unos principados tribales independientes, los que libraron las últimas batallas por el dominio sobre Cartago, el Mediterráneo occidental y África del norte.

Tras deshacer el entuerto, trataremos de rescatar la realidad histórica del pozo en donde las leyendas y coloridas anécdotas de los genealogistas, historiadores y geógrafos musulmanes y

7 El erudito persa Müsä Jarazmi, Muḥammad b. Mūsā al-Kֵhwārizmī, al-Khwarizmi, escribió su obra histórica hacia 810-815 y es la principal fuente de Elías para los años 633 a 787. Las noticias que de él recoge están en su mayoría centradas en Oriente con algunas excepciones. La más notable es que Müsä Jarazmi es la fuente de Elías para el año 91, en el que se recoge el nombramiento de Musa Ibn Nusair, el futuro gobernador de la España musulmana, como gobernador de Ifriqiya. Müsä Jarazmi constituye un informador de primer orden tanto por su credibilidad como por su antigüedad. Por ello él y no la Crónica de los árabes es la fuente de información de Elías de Nísibe sobre la "reina de los romanos", lo cual no iría en detrimento de la solidez de la información. Esta fuente sería tan antigua o más como la de Al-Wākidīì y además, Müsä Jarazmi escribía desde la Bayt al-Hikma, «La casa de la sabiduría», el centro de conocimiento más rico y mejor dotado de su época e íntimamente ligado a la corte califal y a sus archivos. 
los intereses, tabúes y deseos de la historiografía contemporánea la habían sumergido. Y es que se ha producido todo un desenfoque de la cuestión que ha centrado los trabajos e intereses de los estudiosos en los supuestos líderes independientes bereberes, Kusayla y la Kâhina, y se ha dejado de lado la resistencia bizantina. De ahí que, mientras que la guerra de la Kâhina ocupa páginas y páginas en los estudios y obras especializadas, la conquista y reconquista del Cartago bizantino por los árabes apenas si ocupa en ellas unas líneas. Di Silvestre (2012: 100-101) por ejemplo, dedica apenas una página a la conquista de África por Hassân ibn alNu'man al-Ghassâní y de esa página tan sólo cuatro líneas a la conquista de Cartago, quedando el resto centrado en la guerra de la Kâhina.

Kaegi, por su parte, en su monografía sobre la conquista árabe del África bizantina (Kaegi, 2010: 247-248) despacha el magno acontecimiento en página y media con algunas disertaciones y reflexiones en las que los hechos concretos sólo ocupan catorce líneas, una menudencia en comparación con la guerra de la Kâhina que se extiende a lo largo de cuatro páginas (Kaegi, 2010: 249-253).

Francesca Lai, en su tesis doctoral, se ocupaba de la caída de Cartago en poco menos de dos páginas, la mayor parte de las cuales dedica a la reproducción de tradiciones árabes, mientras que los textos y noticias bizantinas brillan por su ausencia. Todo ello a la par que se centra toda la atención en la Kâhina, a la que considera el personaje principal en el drama del fin del África bizantina (Lai, 2009: 126-128).

Mohamed Benabbès, constituye la excepción pues, si bien es cierto que dedica veintitrés páginas a las dos expediciones de Hassân ibn al-Nu'man al-Ghassâní contra Cartago, páginas en las que la Kâhina tiene entrada, aunque no constituye el eje central, dedica la mayor parte de esas páginas a afrontar los problemas toponímicos y cronológicos, mientras que la reconstrucción de los hechos militares y políticos sólo le ocupan poco más de media página. Cabe señalar que Benabbès no usa todas las fuentes bizantinas y, al usar las noticias de Elías de Nísibe a partir de la traducción francesa de Delaporte, no se percata de la importancia vital de su testimonio. Por ello, le sigue atribuyendo a la Kâhina el principal mérito de la derrota y retirada de Hassân ibn al-Nu'man al-Ghassâní y dedica otras veintidós páginas en exclusiva a narrar el enfrentamiento entre la supuesta «reina de los beréberes» y el ejército califal conducido por Hassân ibn al-Nu'man al-Ghassâní (Benabbès, 2004: 280-303). El trabajo de Benabbès, el mejor sin duda sobre la conquista árabe del norte de África, se ve, no obstante, lastrado por esa «fidelidad» absoluta y contradictoria al esquema historiográfico asentado desde el siglo XIX. Así, pese a reproducir los textos árabes referentes a la batalla de Tabudeus (683), donde Kusayla aparece como comandante al mando de tropas romanas a las que se suman auxiliares bereberes, sigue atribuyendo el peso de las operaciones contra 'Uqba ibn Nâf' al-Fihrî a la supuesta coalición bizantino-bereber en la que estos últimos serían el elemento director y las tropas romanas simples auxiliares (Benabbès, 2004: 325-327).

Yves Modéran dedica apenas una página a la conquista árabe de Cartago en el marco de su gran obra sobre los Moros y Bizancio (Modéran, 2003: 688-689), mientras que la Kâhina y las tribus beréberes que supuestamente capitaneaba ocupan escasas páginas (Modéran, 2003: 198-200 y 689-797).

Por último, el profesor Christides, dedicaba tan solo dos páginas, a la caída de Cartago y una buena parte de esas dos páginas se centraba en la Kâhina a la que Christides señalaba como la personalidad decisiva en la resistencia frente al ejército conquistador de Hassân ibn al-Nu'man al-Ghassâní (Christides, 2000: 46-47).

Sin embargo, si se dejan atrás los paradigmas y prejuicios, encontramos que las fuentes islámicas no dejan lugar a dudas y las bizantinas tampoco. Los bizantinos son unánimes: la flota del patricio Juan derrotó a los árabes, entró a viva fuerza en el puerto de Cartago rompiendo 
la cadena que seguía cerrándolo y ocupó no sólo la arruinada Cartago, sino también todas las poblaciones y fortalezas de África (Teófanes, 2007: 370-371; Teodoro Eskutariota, 1894: vol. VII, 115; Manases, 2003: 354-356; Zonarás, 1995: 33-35). Los árabes, por su parte, hacen hincapié en el factor sorpresa del contraataque bizantino y señalan el lugar donde se produjo el golpe más mortífero, Radas, y que la derrota fue tan completa, que Hassan tuvo que enviar una embajada al califa en demanda de refuerzos urgentes ('Abd al-Hakam, 1964: 36-41; AlBaladhuri: 1969: 360-362; Al-Bekri, 1913: 22, 81-84; Al-Maliki, 1969: 143-147; Ibn Al-Athir, 1898: p. 28-31; Tidjani, 1852: 57-208 y 1853: 79-81, 101-168 y 354-425; Ibn 'Idhari, 19011904: 22-30). Algo que corroboran las fuentes bizantinas.

Llegados a este punto debemos plantearnos qué papel desempeñó realmente en todo esto la Kâhina. La historiografía ha desarrollado dos opciones de interpretación: o bien se desliga totalmente a la Kâhina del contragolpe bizantino o bien, teniendo en cuenta los paralelismos insoslayables entre las derrotas árabes ante el patricio Juan y ante la Kâhina y sumando a todo ello los problemas insolubles que agrega la cronología, hacen coincidir ambas derrotas y las relacionan entre sí. Es una reconstrucción más sensata y más acorde con las fuentes, desde luego, pero al mantener el carácter independiente y exclusivamente bereber de la Kâhina, se ve forzada a retorcer las noticias de las fuentes para acomodarlas al paradigma historiográfico imperante desde fines del siglo XIX: los bizantinos no eran el factor militar principal y sólo recuperaron la costa norte de Bizakia (Túnez). La Kâhina y sus bereberes eran los verdaderos rivales de los árabes.

Las seis fuentes bizantinas que hemos citado y que recogen los hechos complementándose entre sí, no hacen referencia a la Kâhina ni a ningún aliado bereber. Se limitan a señalar el triunfo completo del patricio Juan, la reconquista de todo el territorio y la reacción árabe encabezada y dirigida desde Siria por el califa.

Las ocho fuentes islámicas primarias que hemos citado recogen dos derrotas de los árabes: una frente a los bizantinos y la otra frente a los bereberes y romanos de la Kâhina. En ambos casos Hassân Ibn al-Nu'man al-Ghassâní pierde el control del territorio y envía peticiones de auxilio al califa. En ambos casos el califa le envía soldados, marineros y oro para organizar una nueva expedición y recuperar Ifriqiya y acaba teniendo éxito. El paralelismo es tan sorprendente que sumado al «despotismo» de la cronología, no puede dejar lugar a dudas: los relatos islámicos sobre el contragolpe bizantino y sobre el contragolpe supuestamente bereber encabezado por la Kâhina forman parte de unos mismos hechos.

No obstante, ¿se puede fijar una cronología segura? Sí. En primer lugar, se debe apuntar que la numismática nos permite establecer un post quem seguro e indiscutible: Cartago no cayó en manos de los árabes sino después de 695, fecha de la última acuñación conocida de monedas bizantinas en la ceca de Cartago. Establece también un ante quem orientativo: los árabes lograron establecer definitivamente un control estable y seguro sobre Bizakia en 703 (Christides, 2000: 65) pues en esa fecha se acuñaron en Ifriqiya las primeras monedas árabes. Esas monedas se acuñaban siguiendo el modelo bizantino, con una deficiente mezcla de griego y latín en sus inscripciones. Esa fecha es también la que la Crónica de los árabes otorga al final de las operaciones militares de Hassân Ibn al-Nu'man al-Ghassâní en África. Además, en perfecta y sorprendente correspondencia, el año 703 es el señalado por varias fuentes islámicas como el de la construcción y consagración definitiva de la mezquita de Kairuán por Hassân Ibn al-Nu'man al-Ghassâní, un acontecimiento de fuerte carácter religioso y simbólico que marcaba el triunfo incontestable de los árabes y del islam en la disputada Ifriqiya.

Las fuentes bizantinas, por su parte, nos permiten precisar aún más el cuadro cronológico general al señalar que el conjunto de las operaciones que tuvieron lugar en torno a Cartago y a sus sucesivas conquistas y reconquistas se extendieron entre 697 y 698. De hecho, los autores 
bizantinos afirman que tales acontecimientos tuvieron lugar durante el tercer año del Emperador Leoncio y añaden, de forma implícita y precisando algo más, que la reconquista bizantina de la ciudad tuvo lugar antes del último invierno que Leoncio pasó como emperador en el trono constantinopolitano, es decir, antes del invierno de 697-698. En suma, lo que las seis fuentes bizantinas que hemos citado nos están diciendo es que los árabes tomaron por primera vez Cartago en algún momento de la primavera-verano del 697 y que los bizantinos lanzaron su contraataque y reconquistaron Cartago y África, antes de que mediara el otoño de ese mismo año de 697 y que tras el invierno de 697-698, los árabes regresaron, derrotaron a los romanos y reconquistaron Cartago antes de que finalizara el verano de 698. Para septiembre-octubre de este último año, la flota bizantina por ellos derrotada en las cercanías de Cartago estaba ya ocupada en asaltar Constantinopla y deponer al emperador Leoncio.

Ya hemos visto que Elías de Nísibe coincide en esto con los autores bizantinos. Su datación nos permite, además, fijar un post quem cronológico en torno al 30 de marzo de 697 para el inicio de la primera campaña árabe contra Cartago, esto es, Cartago fue tomado por los ejércitos árabes entre abril de 697 y muy pronto fue retomado por los bizantinos antes de mediados de octubre de ese mismo año. Ese era el periodo en que el Mar Mediterráneo permanecía «abierto» a la navegación de grandes flotas y ello coincide con lo que certifican las fuentes bizantinas: la flota romana derrotó a los árabes, reconquistó Cartago y África antes del invierno de 697-698.

Ahora bien, el marroquí Ibn 'Idhari afirma que Hassân Ibn al-Nu'man al-Ghassâní fue nombrado gobernador de Ifriqiya tras la muerte de Zuhayr ibn Qays y luego añade que entró en Ifriqiya en el año 78 de la hégira, a finales de marzo de 697 (Ibn 'Idhārī, 1948-1951: 2223). Esta última fecha cuadraría perfectamente con la que da Elías de Nísibe en su primera noticia sobre Hassân Ibn al-Nu'man al-Ghassâní y con la fecha obtenida de las noticias de las fuentes bizantinas. Benabbès afirma erróneamente que Ibn 'Idhari sitúa el nombramiento de Hassân ibn al-Nu'man al-Ghassâní en 78 de la hégira (Benabbès, 2004: 280-281), pero lo que Ibn 'Idhārī dice literalmente es que en ese año Hassân ibn al-Nu'man al-Ghassâní penetró en Ifriqiya a la cabeza de un ejército de 40.000 hombres y que se dirigió contra Cartago. Además, Ibn 'Idhari precisa que dicho ataque se inició en esa primavera de 697, lo cual se corresponde perfectamente no sólo con la antigua noticia de la Crónica de los árabes, sino también con las fechas de las seis fuentes bizantinas. Como hemos visto, éstas no dejan ningún género de dudas con respecto a que la primera conquista árabe de Cartago tuvo lugar antes del otoño de $697 \mathrm{y}$, gracias a la numismática, sabemos que Cartago seguía en manos bizantinas en 695.

Una vez más y puesto que el resto de las fuentes islámicas no ofrece una fecha precisa, no ya para la batalla por Cartago, sino tampoco para el comienzo del gobierno de Hassân ibn alNu'man al-Ghassâní, ni para sus campañas contra romanos y bereberes, ni aún para su guerra contra la Kâhina, ni tan siquiera para su sustitución como gobernador de Ifriqiya, se prefirió especular. Así Hugh Kennedy fija la fecha de la primera conquista de Cartago en 693 al concluir que la Kâhina fue vencida por Hassân Ibn al-Nu'man al-Ghassâníen 698 y que éste había pasado cinco años refugiado en Cirenaica tras haber sido derrotado y expulsado de África por la Kâhina tras haber «ocupado pacíficamente» una Cartago que él supone semiabandonada. Este autor se desentiende por completo de la segunda conquista árabe de Cartago (Kennedy, 2007: 258-264). Luis García Moreno, por su parte, sitúa el inicio de la ofensiva árabe contra Cartago en 694 y su primera conquista en 695 (García Moreno, 2013: 117-118), fecha en que la coloca también Benabbès (Benabbès, 2004: 282-284). Kaegi prefiere ser menos riguroso y la sitúa entre 695 y 696, fijando la reconquista bizantina, sin dar razón para ello, en 696 y la definitiva conquista islámica en un momento impreciso situado entre 697 y 698 (Kaegi, 2010: 247-248) Christides afirma que la única solución posible, tras combinar las fuentes árabes con 
las bizantinas es situar la primera conquista árabe de Cartago en 697-698, pero no precisa si en un año o en otro. Además, se contradice al fijar la definitiva conquista árabe en 698 pero situándola tras la derrota frente a la Kâhina y afirmando que Hassàn tuvo que huir y aguardar en Kusur Hassan tres años antes de regresar a África y retomar Cartago (Christides, 2000: 46-47). ¿Si la había tomado en 697-698 por primera vez y si tras hacerlo había sido derrotado por la Kâhina y si tras esta derrota pasó tres años en Kusur hassan antes de volver a conquistar Cartago, como es posible que esta segunda conquista de Cartago ocurriera en 698? Sirvan estos pocos ejemplos para mostrar lo abierto e inseguro de la cuestión hasta el presente.

El aparente desacuerdo entre las dataciones islámicas para el comienzo del gobierno de Hassân ibn al-Nu'man al-Ghassâní en Ifriqiya desaparece o al menos se explica, si se tienen en cuenta dos factores. Primero, que cuando se produjo la derrota y muerte de Zuhayr Ibn Qays, el anterior gobernador árabe de Ifriqiya, 688-689, el imperio islámico no sólo se vio arrojado de Ifriqiya casi por completo, tan sólo se mantuvo el control sobre la aislada ciudad de Trípoli y sobre parte de Cirenaica, sino que además su situación interna era de tal gravedad por mor de la guerra civil en Mesopotamia y Arabia, que se hacía muy difícil que el califa atendiera a los problemas de la lejana y secundaria Ifriqiya. En segundo lugar y teniendo en cuenta lo anterior, lo lógico es pensar que, aunque sobre el papel pudiese haber un nuevo gobernador árabe de Ifriqiya, la realidad fuera que este no tomase posesión real y física de su gobierno, ni fuese dotado de los medios militares y económicos necesarios para ejercerlo, hasta que el califa no acabara con los rebeldes en Mesopotamia y Arabia, algo que no ocurrió hasta 692-693. Curiosamente la fecha en la que varias fuentes islámicas coinciden para iniciar el gobierno de Hassân ibn alNu'man al-Ghassâní en Ifriqiya. Por si esto fuera poco, una de las fuentes árabes más precisas, la obra de Ibn Al-Athir, no deja lugar a la especulación y certifica esto mismo, diciendo que el califa no envió a Ifriqiya al nuevo gobernador, ni lo proveyó de tropas y oro, hasta haber derrotado a los rebeldes que lo atosigaban en Oriente. De hecho, Ibn Al-Athir fija estos acontecimientos en mayo de 693 (Ibn Al-Athir, 1898: 28).

Ahora bien, los argumentos arriba expuestos hacen imposible que los acontecimientos de 697 y 698, la guerra contra Bizancio y contra la Kâhina, puedan ser disociados. ¿Cómo conjugarlos entonces? La Crónica de los árabes nos da la clave. Esta obra soluciona el problema al atribuir la derrota de Hassân ibn al-Nu'man al-Ghassâní no a la «reina de los bereberes» sino a «los reyes». Además, puesto que la propia Crónica de los árabes afirmaba una línea antes que Hassân Ibn al-Nu'man al-Ghassâní había entrado en el país de los rum, esos «reyes» que lo sorprenden tras su triunfo inicial, sólo pueden ser «reyes» de los rum. Así aparece ya recogido y esbozado en la Crónica de los árabes. Lo anterior, sin embargo, no sólo cuadra con lo que los historiadores bizantinos y árabes han transmitido sobre los combates entre Hassân ibn alNu'man al-Ghassâní y el patricio Juan, sino que además cuadra con lo que una de las fuentes árabes más antiguas y fiables nos dice sobre la guerra de la Kâhina: que no fue ella, sino su general, el mismo que había combatido como segundo en las filas de Kusayla, quien realmente derrotó a Hassân ibn al-Nu'man al-Ghassâní y sus árabes (Al-Bekri, 1913: 22-23).

Con respecto a Kusayla cabe señalar que fue también un general romano a la cabeza de contingentes romanos (Soto Chica, 2015a: 484). De ahí que 'Abd al-Hakam diga que Kusayla comandaba tropas romanas y beréberes y al-Bekri que era el comandante de las tropas romanas y que una vez puestas éstas en marcha contra 'Uqba se le sumaron contingentes bereberes. El Kitâb al-Istibçar concreta que Kusayla era el comandante de las tropas romanas de Tabudeus, mientras que Al-Mâlikî insiste en que las tropas que defendieron Tabudeus de los árabes eran romanas y que Kusayla cayó sobre los árabes al mando de un contingente formado por romanos y bereberes. Ibn Al-Athir y Al-Nuwairi, más tardíos, hacen lo mismo en esencia. Si 
bien es cierto que hacen mayor hincapié en el carácter bereber de Kusayla pero sin excluir el elemento romano en la batalla de Tabudeus.

Así pues, en las fuentes árabes más antiguas Kusayla es un jefe de tropas romanas a las que se suman, siempre en segundo lugar y sin tener ellas la iniciativa militar, tropas auxiliares bereberes. Pero si Kusayla es un jefe de tropas bizantinas, ¿quién puede ser ese general suyo que capitaneaba los contingentes inflamados por la mística Kâhina? Pues un jefe, un oficial bizantino. De hecho, las propias fuentes islámicas nos dan dos opciones al respecto que podemos valorar. Pudo tratarse del Turmarca o jefe de la guarnición de Iustiniana Capsa que aparece en Tabudeus luchando junto a Kusayla y liberando a algunos prisioneros árabes. Un jefe romano, sin duda, pues como señalan las fuentes árabes Iustiniana Capsa nunca había sido tomada por los árabes antes de la definitiva caída de Cartago y su «Romanidad» era tan acusada, que todavía en la segunda mitad del siglo XII era evidente e insoslayable: «Los habitantes de Gapsa son romanos berberizados que hablan la lengua romana», nos dice Idrisi (Idrisi III clima, 104), lo que resta toda credibilidad al tardío relato del siglo XIV de Ibn Jaldûn, quien transforma al jefe de Iustiniana Capsa en un jefe bereber. También pudo ser ese «amigo» de Kusayla al que el propio Ibn Jaldûn da nombre: Sekerdif Al-Rumi, esto es Sekerdif el Romano (Modéran, 2005: 428). En todo caso, ambos jefes militares relacionados con Kusayla, el jefe de Capsa, presente en los combates de Tabudeus y el amigo de Kusayla, señalan a una identidad romana, bizantina. Al-Bekri, siempre tan preciso y escribiendo en el siglo XI noticias que se remontaban al VIII y al IX, nos informa de que la batalla en la que este general derrotó a Hassan tuvo lugar en Tacape/Gabes. Así pues, se puede concluir que uno de esos «reyes» de la Crónica de los árabes que derrotaron a Hassân al-Ghassaní a fines del verano de 697 tuvo que ser el jefe romano de las tropas de Iustiniana Capsa.

En efecto, si situamos en un mapa lo dicho, todo cobra lógica militar. Cartago, Radas y Tacape/Gabes son los lugares de batalla y derrota de Hassân al-Ghassaní y sus tropas. Por lo tanto, si tenemos en cuenta la geografía, el punto final de la retirada de Hassân al-Ghassaní, Kusur Hassan, una posición a unos 100 kilómetros al este de Trípoli, y los movimientos previos de árabes y bizantinos, la reconstrucción, hipotética pero lógica, sería: en primer lugar, el patricio Juan sorprende a la flota y a las tropas árabes en Radas y Cartago y las derrota. A continuación, Hassân al-Ghassaní reúne los restos de su ejército y se retira ante el éxito del desembarco bizantino y ante su avance hacia el interior y hacia el este. Seguidamente, Hassân Ibn al-Nu'man al-Ghassâní, en su ruta de retirada hacia Trípoli, su base de partida y abastecimiento, se aleja de la costa pues, sin su flota, destruida en Radas, debía de temer los ataques de la victoriosa flota bizantina y por ende, tuvo que pasar entre Iustiniana Capsa y Tacape/ Gabes en su retirada hacia Trípoli. Subsiguientemente, los contingentes bizantinos de Tisrus/ El-Djem, Iustiniana Capsa/Gapsa, Castele/Castilia y Tacape/Gabes que habían sido dejados atrás por el fulgurante avance de Hassân ibn al-Nu'man al-Ghassâní hacia Cartago, reforzados por auxiliares bereberes y por destacamentos romanos llegados desde Numidia, comandados por el «lugarteniente de Kusayla»y por los comandantes locales, «se toparon» como dice la Crónica de los árabes usando un término que sugiere sorpresa, y lo derrotaron nuevamente en las cercanías de Tacape/Gabes. Por último, Hassân ibn al-Nu'man al-Ghassâní —y en esto todos los autores islámicos concuerdan - se retiró apresuradamente hacia Trípoli y de allí a Kusur Hassan, a 100 kilómetros al este de Trípoli y a unos 70 kilómetros de la costa.

¿Y la Kâhina? Fue lo que su nombre indica y lo que indica su genealogía y el contexto histórico en el vivió, el África bizantina de la segunda mitad del siglo VII, una noble de origen bizantino-bereber dotada de gran carisma religioso, una profetisa que inflamó los decaídos corazones africanos y los animó. Ahora bien, si sopesamos las noticias sobre la Kâhina que ya hemos expuesto, nos llaman la atención varias cosas: en primer lugar, las batallas, aliados, 
vasallos y rebeldes relacionados con la Kâhina se vinculan con ciudades romanas de Bizakia: Tacape/Gabes, Tisrus/El-Djem, Tabraca/Tabarca, aliados, primero y rebeldes después, Iustiniana Capsa/Gapsa, Tacape/Gabes y Castele. En segundo lugar, sus tropas son tanto romanas como bereberes. Por último, sus antepasados tienen nombre bizantino, Teófanes y Mateo, su marido fue un romano y de sus dos hijos, uno tiene identidad bereber y el otro romana.

Todo esto apunta a lo que ya hemos expuesto. Se podría argumentar que también se señalan batallas y lugares relacionados con la Kâhina en la región de Numidia y más concretamente en la del Aurés y también en lugares tan excéntricos como el Oasis de Gadames en el Fezzán. Es cierto, pero es que la Kâhina se fue transformando en el «aderezo» imprescindible en cualquier recuerdo de resistencia frente al avance islámico y de ahí que figure desde el sur de la actual Libia hasta el este del actual Marruecos. Sin embargo, esas identificaciones, no son nada claras, al contrario que las de Tacape/Gabes, Tisrus/El-Djem, Tabraca/Tabarca, Iustiniana capsa/gapsa o Castele.

En cuanto a la ciudad de Bagralla, en Numidia, sin duda se trata de una corrupción de Vaga, la Bedja o Badja árabe, una ciudad de campiña riquísima situada a 47 kilómetros al suroeste de Tabraca/Tabarca, donde todos los historiadores islámicos señalan combates de Hassân ibn al-Nu'man al-Ghassâní con tropas bizantinas tras la definitiva caída de Cartago. Vaga estaba situada a unos 45 kilómetros de Tabraca/Tabarca, ciudad que Al-Bekri señala como lugar de la muerte de la Kâhina (Al-Bekri, 1913: 121). ¿Pero no nos dicen el resto de las fuentes islámicas que la Kâhina murió en Tarfa? Sí, y a escasos kilómetros de Tabraca/Tabarca, en su territorio y en la región de Sasfura que una y otra vez señalan los autores islámicos como lugar de combates entre los árabes de Hassan y los bizantinos y sus aliados bereberes, se hallaba Tarfa El-Djoun, esto es, «la punta de la bahía», un cabo o punta que cierra una ensenada situada en el camino entre Tabraca/Tabarca e Hipo Dyarrhytus/Bizerta y que es señalada por el geógrafo Idrisi (Idrisi III clima, 104) Esto parece más lógico, pues pone de acuerdo a Al-Bekri con el resto y no fuerza el resto de noticias que tenemos sobre las acciones bélicas del momento. Tarfa es un topónimo harto frecuente e impreciso. Según se escriba puede significar punta/cabo o tamarisco y en ambos casos todo el Magreb está lleno de topónimos con ese nombre. Pero Tarfa El-Djoun tiene la virtud de estar junto a Tabraca/Tabarca, ciudad señalada por el preciso y siempre bien informado Al-Bekri como el sitio donde fue derrotada y muerta la Kâhina. Además, todas las fuentes islámicas señalan la región en torno a Tabraca/Tabarca, desde Hipo Dyarrhytus/Bizerta a Constantina/Bonne, actual Annaba, como una región donde se libraron recios, prolongados y no concluyentes combates entre los contingentes bizantinos y sus aliados bereberes por un lado y las tropas de Hassan por otro.

En conclusión, la Kâhina no fue sino una líder mística y profética, una suerte de profetisa Shajah africana que ayudó a los generales bizantino-africanos y al patricio Juan a recomponer las fuerzas y el ánimo de los africanos frente a los árabes. Su carácter anecdótico, singular y religioso agrandó su imagen y su actuación y opacó la de los jefes militares bizantinos. Por eso aciertan las fuentes bizantinas al centrarse en el jefe de la fuerza más imponente: el patricio Juan y por eso acierta también la Crónica de los árabes, que atribuye la derrota de Hassan, no a ninguna reina de los bereberes, sino a unos reyes de los romanos: El patricio Juan, sus turmarcas y drungarios y al jefe de las tropas romanas africanas, posiblemente el antiguo lugarteniente de Kusayla, cuyos hombres fueron galvanizados por las prédicas y visiones de la Kâhina, la líder africano-romana que entre 697 y 703 se opuso al sometimiento de su tierra por los árabes. 


\section{BIBLIOGRAFÍA}

'Abd al-Hakam (1964): Futūh Ifrīqiya wa-al-Andalus. Bayrūt, Maktabat al-Madrasah wa-Dār al-Kitāb al-Lubnānī lil-Ṭibā'ah wa-al-Nashr.

Al-Baladhuri (1969): Kitab Futuh Al-Buldan, P. K. Hitti (trad.). Nueva York, Columbia University Press.

Al-Bekri (1913): Description de L'Afrique septentrionale par El-Bekri, M. De Slane (ed.). París.

Al-Maliki (1969): «Le récit d'al-Mālikī sur la conquête de l'Ifrīqiya. Traduction annotée et examen critique», H. R. Idris (ed.). Revue des Etudes Islamiques 37, 117-149.

Ananías de Shirak (1992): The Geography of Ananias of Širak (AŠXARHAC'OYC'): The long and the short recensions, R. H. Hewsen (ed.). Wiesbaden, Reichert.

Benabbès, M. (2004): L'afrique byzantine face à la conquête arabe. Recherche sur le VII siècle en Afrique du Nord. Universidad París X Nanterre.

Christides, V. (2000): Byzantine Libya and the March of the Arabs towards the West of North Africa. Oxford, Oxford University Press.

Di Silvestre, S. (2012): Dall'Africa romana all'Ifriqiya musulmana, un territorio in transizione. Analisi della transfomazioni urbane. Venecia.

Diehl, Ch. (1896): L'Afrique Byzantine. Histoire de la domination Byzantine en Afrique (533-709). París, Lerroux.

Elías de Nísibe (1884): Fragmente syrischer und arabischer Historiker, F. Baethgen (ed.). Leipzig, Gorgias Press.

Elías de Nísibe (1909-1910): Opus Chronologicum, Corpus Scriptorum Christianorum Orientalium: Scriptores Syri Textus, E. W. Brooks y J. B. Chabot (eds.). Rome, Paris.

Elías de Nísibe (1910): La Chronographie d'Élie Bar-Šinaya, Métropolitain de Nisibe, L. J. Delaporte (ed.). Paris, Librairie Honoré Champion.

Fournel, H. (1875): Études sur la Conquête de l'Afrique par les Arabes d'après les textes arabes imprimés. París, Imprimerie National.

García Moreno, L. (2013): España 702-719: la conquista musulmana. Sevilla, Universidad de Sevilla.

Gil Egea, M. E. (2015): «Los bereberes judíos de Ibn Jaldûn. La leyenda y su utilización», L. García-Moreno et alii (eds.), Historiografia y Representaciones III. Estudios sobre las fuentes de la conquista islámica. Madrid, Real Academia de la Historia: 517-541.

Ibn 'Abd al-Hakam (1966): Futūh Ifrìqiya wa-al-Andalus. Conquista de África del Norte y de España, E. Vidal Beltrán (ed.).Valencia, Anubar.

Ibn Al-Athir (1898): Ibn-el-Athir. Annales du Maghreb et de l'Espagne, E. Fagnan (ed.). Argel, Typographie Adolphe Jourdan.

Ibn 'Idhari (1901-1904): Histoire de l'Afrique et de l'Espagne intitulé al-Bayano'l-Mogrib, E. Fagnan (ed.). Argel, Imprimerie orientale P. Fontana et cie.

Ibn Idhārī (1948-1951): Histoire de l'Afrique du Nord et de l'Espagne musulmane, intitulée Kitāb albayān al-Mughrib, et fragments de la chronique de 'Arib, R. Dozy (ed.). Leiden, E. J. Brill.

Ibn Jaldûn (1925): Ibn Jaldûn. Histoire des Berbères, M. De Slane (ed.). París, 4 vols., reedit. 1969.

Ibn Khurradâdhbih (1949): «Kitab al Masalik wa'1-Mamalik», M. Hadj-Sadok (ed.). Description du Maghreb et de l'Europe au IIIe-IX siècle. Argel, Editions Carbonel.

Ibn Rustih (1949): «Kitab Al-A»lâq An-Nafisa», M. Hadj-Sadok (ed.), Description du Maghreb et de l'Europe au IIIe-IX siècle. Argel, Editions Carbonel.

Kaegi, W. (2010): Muslim expansion and Byzantine Collapse in North Africa. Cambridge, Cambridge University Press.

Kennedy, H. (2007): Las grandes conquistas árabes. Barcelona, Grupo Planeta.

Kitâb Al-Istibçar (1899): «L' Afrique Septentrionale au XII siècle de notre ère», E. Fagnan (trad.), Recueil des notices et mémoires de la Société Archéologique de Constantine, 1-229.

Lai, Francesca (2009): Le vie della conquista araba nell'Africa del Nord. Universita' degli studi di Sassari.

Maldonado Villena, F. J. y Soto Chica, J. (eds.) (2016): La Didascalia de Jacob. Edición, traducción y estudio. Granada, Centro de Estudios Bizantinos, Neogriegos y Chipriotas.

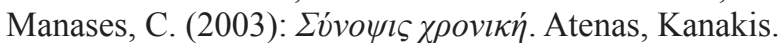

Migne, J. P. (1862): «Exemplar Divinae Jussionis Justiniani Augusti Ad Ioannem II Papam». Patrología Latina. MPL096 0425 - 0428B. 
Migne, J. P. (1863): «Notitiae graecorum episcopatuum, a Leone Sapiente ad Andronicum Palaeologum», Patrología Graeca, 107, 0329.

Modéran, Y. (2003): Les Maures et l'Afrique Romain (IVE-VIII ${ }^{e}$ s.). Roma, École Française de Rome.

Modéran, Y. (2005): «Kusayla, l'Afrique et les Arabes», Identités et cultures dans la Algérie antique, Actes du colloque international de Rouen, mai 2003. Rouen, Université de Rouen: 423-457.

Modéran, Y. (2006): «De Mastics à la Kâhina». Aouras, 3: 158-183.

Soto Chica, J. (2015a): «África disputada. Los últimos años del África Bizantina», L. García-Moreno et alii (eds.), Historiografía y Representaciones III. Estudios sobre las fuentes de la conquista islámica. Madrid, Real Academia de la Historia: 457-514.

Soto Chica, J. (2015b): «Egipto los árabes y la conquista de la Libia Marmárica, Pentápolis y tripolitania (642-698)», L. García-Moreno et alii (eds.), Historiografía y Representaciones III. Estudios sobre las fuentes de la conquista islámica. Madrid, Real Academia de la Historia: 541-606.

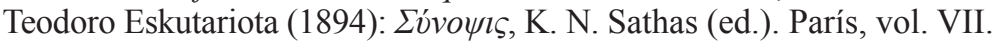

Teófanes (2007): Xoovoroyía, A. A. Koustenis (ed.). Atenas, Armós, t. A'.

Tidjani (1852-1853): «Voyage du Scheikh et-Tidjani dans la Régence de Tunis, pendant les années 706, 707 et 708 de l'Hégire», A. Rousseau (ed.). Journal Asiatique, 4 série 20 (aout-septembre 1852), 57-208 y 5 série (février-mars 1853).

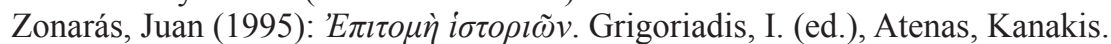

Zuckerman, C. (2002): «La haute hiérarchie militaire en Afrique byzantine». Antiquité tardive, 10, 169175.

\section{RECURSOS EN LÍNEA}

Leder, Stefan, «Al-Wāḳidī», en Bearman, Peri, Bianquis, Thierry, Bosworth, Clifford Edmund, van Donzel, Emeri, Heinrichs, Wolfhart (eds.) Encyclopaedia of Islam, Second Edition, Consulted online on 05 July 2016.https://doi.org/10.1163/1573-3912 islam_SIM_7836

Al-Idrisi, Description de l'Afrique et de l'Espagne, en http://penelope.uchicago.edu/Thayer/F/Gazetteer/Periods/medieval/_Texts/Idrisi/3A*.html

Recibido: 18-08-2018

Aceptado: 29-03-2019 